\title{
The structure and growth of valve-pocket thrombi in femoral veins
}

\author{
SIMON SEVITT
}

From the Department of Pathology, Birmingham Accident Hospital

SYNOPSIS The structure of 50 small thrombi in femoral valve pockets and the microscopic contents of 35 apparently empty pockets were studied in an attempt to ascertain the nature of the microscopic nidi from which thrombi form and their manner of growth to visible thrombi. Sixteen thrombi had little or no cellular invasion. Most of these recent structures had two main regions, red areas restricted distally in the pocket by the vein wall, and larger white regions comprising most of the thrombus length and often covering the red areas. Red areas are the early sites of cellular adhesion and invasion and the likely sites of origin of most thrombi. They were usually dominated by red cells and fibrin. White zones, which represent propagation growth, are characterized by many foci of platelets with fibrin borders (platelet-fibrin units). Some red areas also contained platelet-fibrin units but they were few and tiny; platelets were not seen in others and one small wholly red thrombus was devoid of platelets. Degenerative changes in platelet-fibrin units were observed, and it is postulated that many become purely fibrin structures. There was no significant evidence of preceding intimal damage in the vein wall. Therefore nidi are laid down on normal endothelium probably on the vein wall near the apex of the pocket. Some pockets, empty of thrombi, contained condensed foci of red cells or tiny fibrin fragments surfaced by endothelial cells and considered to be the remnants of aborted thrombi; a few contained clumps of platelets or leucocytes. It is postulated that any of these may represent the nidi from which thrombi grow. Several thrombi also incorporated large fat droplets, numerous in two. Fat embolic globules derived from fractures are their likely source.

Small isolated thrombi in valve pockets (valve sinuses) are not infrequent in major deep veins of the thigh (fig 1) and calf, especially in middle-aged and elderly subjects at bed rest (McLachlin and Paterson, 1951; Paterson and McLachlin, 1954; Gibbs, 1957; Sevitt and Gallagher, 1959, 1961; Sandritter, 1962; Cotton and Clark, 1965; Hume, Sevitt, and Thomas, 1970; Diener, 1971). They grow by an additive process and are one of the main sources of long thrombi in deep veins with their danger of embolism. Histological aspects of valve-pocket thrombi have been reported only by Paterson and McLachlin (1954) and Paterson (1969), and little is known of the microscopic nidi from which they grow and the transformation to visible thrombi. These are not unimportant because of the controversy whether or not all thrombi begin as foci of clumped platelets on sites of endothelial damage (Hume, Sevitt, and Thomas, 1970; Thomas, 1972) and because of the implications for progress in prophyReceived for publication 9 April 1974. lactic measures. Early structure and growth are the main concern of this study, a preliminary report of which has been outlined elsewhere (Sevitt, 1973b). Thrombi in femoral valve-pockets were investigated largely because of ease of collection, but there is no reason to believe that they differ from those in calf and other veins except for differences imposed by the sizes of the pockets.

\section{Material and Methods}

Fifty femoral valve-pocket thrombi collected over 15 years were studied. They came from 41 injured or burned subjects (27 women) most of whom were elderly and 23 of whom had hip fractures (see table). Courses of oral anticoagulant drugs had been given to 27 patients, begun days or weeks after injury in seven and terminated days or weeks before death in 13 subjects. Thrombi were revealed at necropsy during systematic exposure of the deep veins of the lower limbs (Sevitt and Gallagher, 1959, 1961). 


\begin{tabular}{|c|c|c|c|}
\hline & \multicolumn{2}{|c|}{ With Femoral Valve Pocket Thrombi } & \multirow{2}{*}{$\begin{array}{l}\text { With 'Empty' Femoral Valve } \\
\text { Pockets }\end{array}$} \\
\hline & Total & Those with Recent Thrombi & \\
\hline No. of patients (females) & $41(27)$ & $14(11)$ & $10(3)$ \\
\hline $\begin{array}{l}\text { Age range (yr) } \\
60-80 \\
\text { Over } 80\end{array}$ & $\begin{array}{l}23-92 \\
11 \\
26\end{array}$ & $\begin{array}{l}23-90 \\
7 \\
6\end{array}$ & $\begin{array}{l}26-92 \\
3 \\
4\end{array}$ \\
\hline $\begin{array}{l}\text { Fractured hip } \\
\text { Other femoral fracture } \\
\text { Other trauma } \\
\text { Burns }\end{array}$ & $\begin{array}{r}23 \\
5 \\
9 \\
4\end{array}$ & $\begin{array}{l}9 \\
2 \\
2 \\
1\end{array}$ & $\begin{array}{l}2 \\
1 \\
5 \\
2\end{array}$ \\
\hline $\begin{array}{l}\text { Survival after accident: } \\
<1 \text { wk } \\
1-4 \text { wk } \\
>4 \text { wk }\end{array}$ & $\begin{array}{r}4 \\
21 \\
16\end{array}$ & $\begin{array}{r}2 \\
10 \\
2\end{array}$ & $\begin{array}{l}3 \\
4 \\
3\end{array}$ \\
\hline Oral anticoagulant therapy ${ }^{1}$ & 27 & 7 & 2 \\
\hline
\end{tabular}

One subject provided four thrombi, six two thrombi each, and the others came from individual patients. The sources were common femoral veins (21 thrombi), deep femoral (16), and superficial femoral veins (13). Deep vein thrombi were also found elsewhere in the lower limbs in 29 subjects.

Most thrombi were photographed in situ or after excision. The opened vein was excised proximal and distal to the thrombus, and most specimens were pinned on to corkboard before fixation in neutral formol saline. Forty-five thrombi were sectioned within their pockets, most (35) lengthwise along the middle of the cusp thereby providing longitudinal sections of undisplaced thrombi. Five others became dislodged from the pockets and were also sectioned $ㅇ$ longitudinally. One half or both halves (six thrombi) $\rightarrow$ were processed into paraffin wax and sections were $c$ stained by standard techniques to obtain details of fibrin, platelets, haemosiderin, surfacing and invad- $\vec{\varphi}$ ing cells, and collagen. Serial sections were prepared $\stackrel{A}{A}$ from one or both halves of 12 thrombi. Frozen sections stained by oil red $\mathrm{O}$ were also prepared from the remaining halves of two thrombi to confirm the nature of fat-like spaces seen in the paraffin sections.

To help to decide the nature of thrombus nidi, the histological contents of 35 femoral valve pockets which seemed macroscopically free of thrombi were also investigated (vide infra).

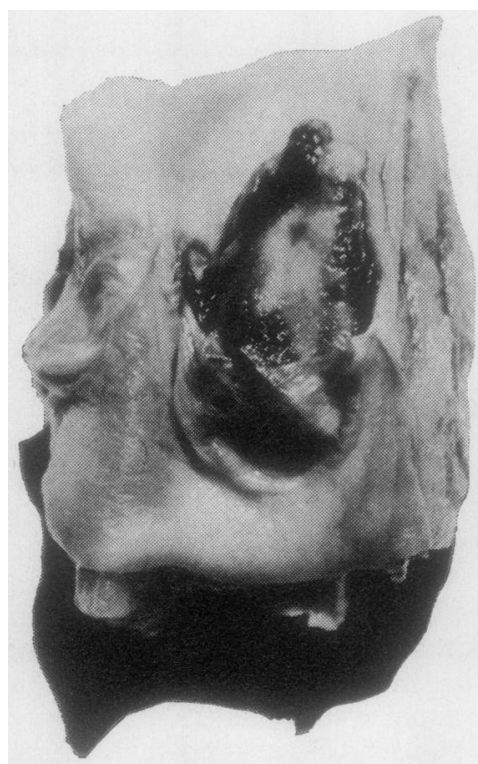

Fig 1a

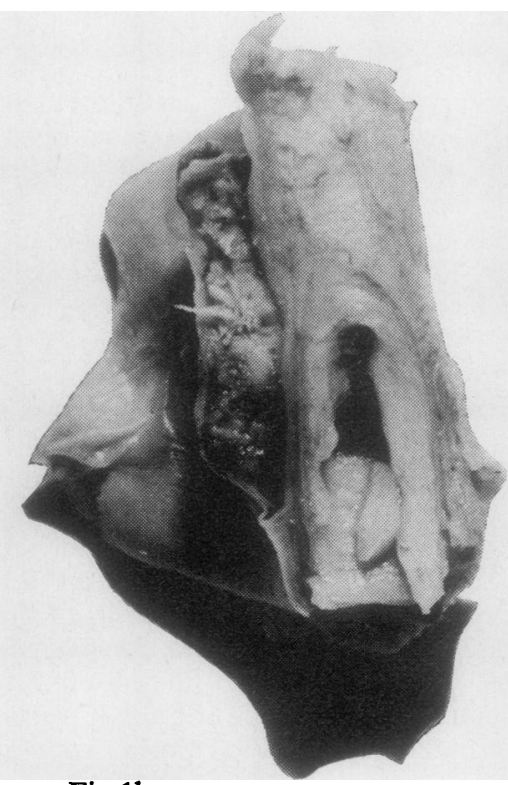

Fig 1 b
Fig 1 Femoral valve pocket thrombus. a. Surface view. $b$. Longitudinal division. Note the predominantly white character of the proximal part (above) compared with the red (dark) colour at the distal end. 


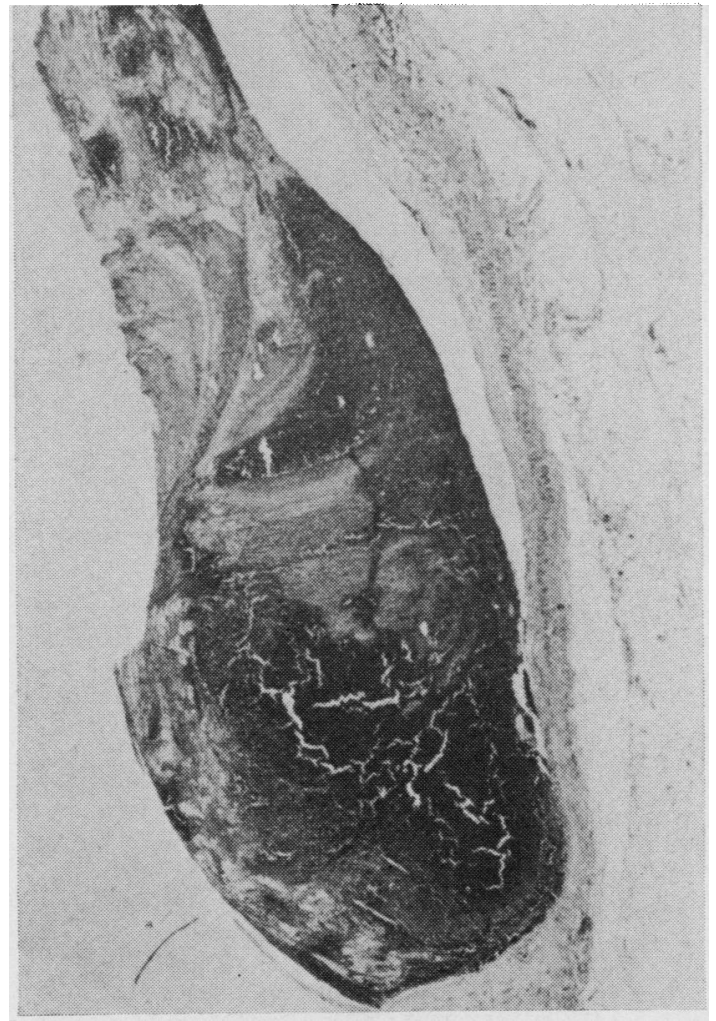

Fig 2 Valve-pocket thrombus propagating from the mouth of a pocket. Note the large 'red area' (dark coloured) distally towards the vein wall; it is covered by white propagated thrombus proximally (above) and on the surface facing the valve leaf. Phosphotungstic acid haematoxylin $\times 15$.

\section{Results}

Thrombi were found in only one of the two valve pockets. Many occupied most of the pocket area, often extending beyond it (fig 1). Most narrowed distally (in the anatomical sense) often becoming angular in longitudinal section and pointing into the apex of the pocket (fig 1b). The apex of the thrombus was usually located a little proximal (central) to the apex of the pocket. As a measure of age the thrombi were classified according to fibrocellular invasion and anchoring. The earliest site of adherence to the vein and of cellular invasion was the external surface towards the apex and often the apex itself, which indicated that this zone was the oldest part of the thrombus. Thirty-four thrombi showed considerable or extensive fibrocellular invasion, often with much collagen and haemosiderin and consequently their value was limited in assessing early structure and growth. The other 16 thrombi provided most of this evidence. Cellular invasion was absent in nine and was very restricted in the others. They are considered together as recent thrombi.

\section{Recent Valve Pocket Thrombi}

The 16 recent thrombi came from 14 patients, mostly elderly and female and many with a fractured hip (see table). Eleven thrombi were in common femoral veins. Ten were sectioned serially.

The nine thrombi without cellular invasion varied between 3 and $9 \mathrm{~mm}$ long and at least five were confined within the pocket area. Parts of five were

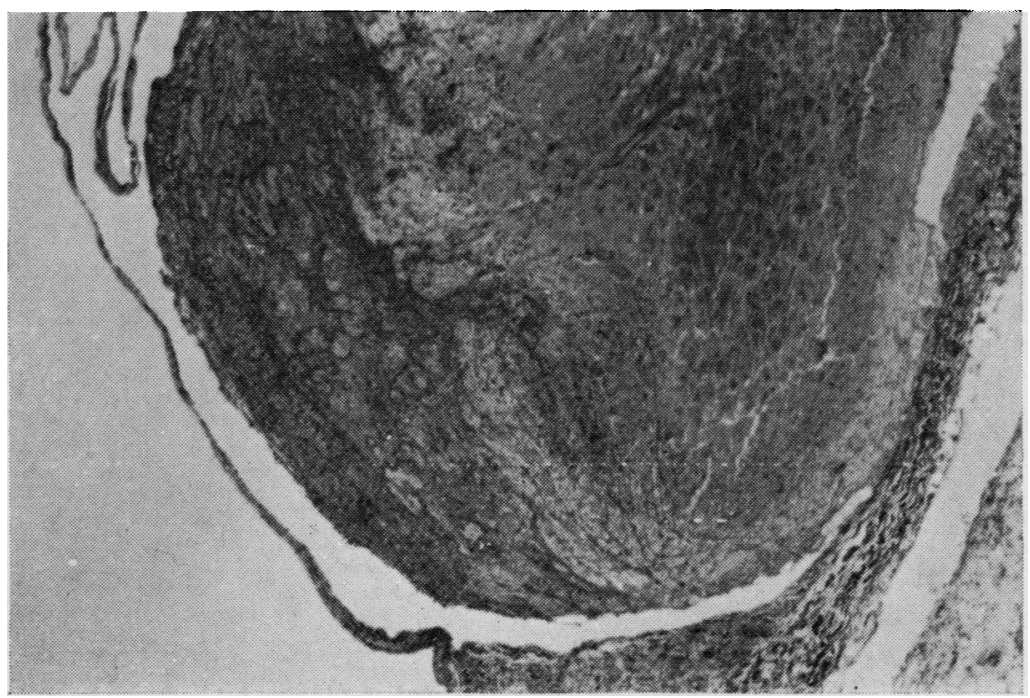

Fig 3 Distal end of thrombus in figure 2. Large red area (right) partly adhering to the vein wall, and covered by white propagated thrombus facing the valve-cusp (left). Picromallory $(P M) \times 30$. 


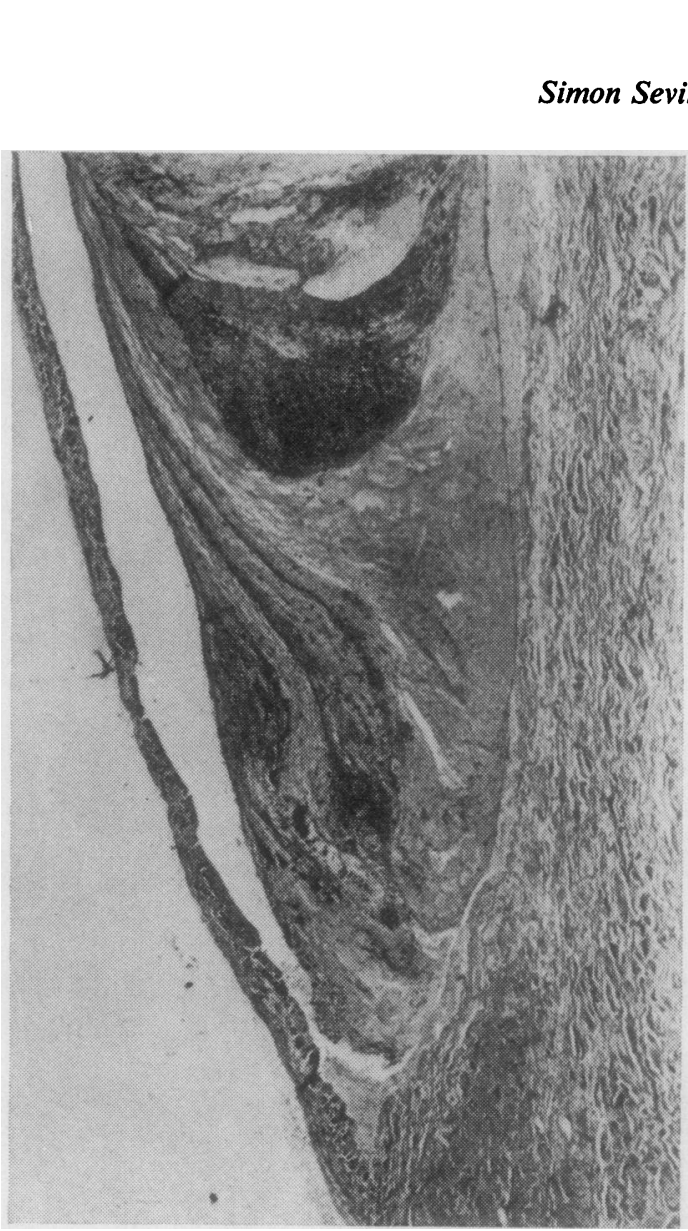

Fig 5 Distal part of a valve-pocket thrombus. Triangular red area adhering to the vein wall (right) and overlaid on left by propagated, laminated thrombus. $P M \times 30$.

multiple foci of clumped platelets rimmed by fibrin (platelet-fibrin units). PM $\times 120$.

already surfaced by a single layer of flat cells, slightly in four thrombi, mainly derived from intimal endothelium near the area attached to the vein. Four became dislodged from the pocket during handling. The seven with slight cellular invasion ranged from 2 to $13 \mathrm{~mm}$ long and each was partly surfaced by endothelial cells, four extensively. One became dislodged during handling.

Macroscopically, the distal end of most thrombi had a general red appearance contrasting often with a whitish or variegated colour proximally (fig 1b). Histologically also, most of the thrombi had two main regions corresponding to those seen macroscopically. The red and white areas have different significance.

Red areas were located distally and laterally, bordering the vein wall and most were dominated by closely packed red cells with striae of fibrin and some leucocytes (figs 2, 3, and 5). Some possessed tiny collections of platelets (vide infra). In two red

areas leucocytes were very numerous and the fibrin structure was more prominent than the red cell $\frac{\text { ㅇ }}{3}$ component. Red areas correspond to the site of early adherence and cellular invasion and hence $?$ are the oldest parts of the thrombi. Some were small $\frac{}{0}$ but others formed most or even the whole thickness of the distal thrombus. Some incorporated the $N$ apex but others were covered by predominantly white $N$ thrombus material which extended down the inner $N$ surface (facing the valve cusp) to the apex (figs $3 \mathrm{\omega}$ and 5). Excluding the wholly red thrombus (vide infra), the sizes of red areas varied from 1 to $5 \mathrm{~mm}$ 을 long and 0.8 to $2.0 \mathrm{~mm}$ wide in longitudinal sections.

White zones were located proximally (figs $2 ?^{+}$ and 4) often comprising most of the thrombus length, and also covered the inner aspect of many $\underset{\mathbb{D}}{\vec{d}}$ red zones (fig 3). White regions represent $\frac{\rho}{\mathbb{Q}}$ propagation. They are characterized by multiple, $\varrho$ well defined collections of packed platelets closely rimmed by fibrin and surrounded by a red cell fibrin $\delta$ 
network (fig 4). Leucocytes are frequent peripherally, sometimes in dense collections. These platelet-fibrin units are well known in thrombi. Some are large and prominent; most are irregularly oval, sinuous, or coralline in outline; and many present as multiple columns. Often they are bigger and more numerous at the proximal end than elsewhere, a feature indicative of active growth. Many measured 100 to 300 micra diameter though many were smaller and some larger, a few up to $1 \mathrm{~mm}$ long or even longer. Sizes of course are partly dependent on the plane of section. Elongated units were generally orientated at right angles to the direction of growth, and a longitudinal direction was usual in the inner part of the thrombus (fig 3). Proximal white areas were present in 15 of the 16 recent thrombi and also in the great majority of organizing thrombi, though extent and degree varied.

The fibrin structure often varied in different regions, the patterns indicating appositional growth from within the red area. Distally, well defined longitudinally arranged lamellae were frequent, the pattern broken by oblique striae passing away from the midline towards the edges in a fan-like fashion. The dominant longitudinal pattern in some thrombi was located distally facing the valve cusp (fig 3 ) and sometimes the fibrin bands looped around the apex and then passed proximally to the red area. Serial sections of several thrombi revealed a series of ovally arranged concentric bands of fibrin in sections away from the midline indicative of fan-like outward growth from the original red area. Proximally,' much of the fibrin was arranged in a transverse or oblique manner largely orientated to the plateletfibrin units, and this pattern merged with oblique striae passing distally to longitudinal bands.

THROMBUS LENGTH AND PROPAGATION Thirty-six thrombi had been measured and a relationship was found between length and proximal propagation based on platelet-fibrin units. Mean length was $6.0 \mathrm{~mm}$ in six thrombi with little or no propagation (range 2 to $10 \mathrm{~mm}$ long) and $6.0 \mathrm{~mm}$ in nine thrombi with some $(+)$ propagation (range 2 to $10 \mathrm{~mm}$ long); but it was $8.6 \mathrm{~mm}$ among 15 thrombi with more extensive propagation $(++)$ (range 2 to $15 \mathrm{~mm}$ long) and $15.7 \mathrm{~mm}$ among six thrombi with considerable propagation (range 7 to $25 \mathrm{~mm}$ long). Mean length was less related to age as assessed by fibrocellular organization. It was $7,8,10$, and $9.5 \mathrm{~mm}$ respectively among five, seven, eight, and 14 thrombi with $0,+,++$, and +++ organization. The two most organized thrombi were only 2 and $7 \mathrm{~mm}$ long. Thus organization and growth are independent entities.
STRUCTURAL DIFFERENCES

Differences as well as similarities were found, and were particularly studied in the 10 recent thrombi subjected to serial section. Seven possessed red areas sited distally and laterally by the vein wall as already described, covered in five thrombi by propagated material containing platelet-fibrin units. Nine had proximal zones of propagation, extensive in four thrombi.

One thrombus had large masses of rimmed platelet collections along nearly all its length and only a very small red area which contained mononuclear cells with phagocytosed platelets by the area of adhesion to the vein.

The red areas of two thrombi which had become dislodged were not circumscribed by overlying propagated thrombus but extended from the apex to a proximal zone of propagated thrombus containing platelet-fibrin units. In one thrombus the latter were numerous though small, but were relatively large though scarce in the other. One was characterized by very large numbers of leucocytes and by many fat spaces, especially in the proximal half, parts superficially resembling adipose tissue (fig 10). The red area of the other contained tiny fibrin-bordered platelet clumps which extended to within $0.1 \mathrm{~mm}$ of the apex (fig $6 \mathrm{a}$ ), and midline sections also revealed unequivocal platelets diffusely arranged and not bordered by fibrin (fig $6 \mathrm{~b}$ ).

One early thrombus (6 mm long) had a wholly red structure, the only completely red thrombus found. It became dislodged during excision of an apparently empty valve pocket. Its condensed structure and slight focal surfacing by flat migrating cells confirmed its antemortem nature. It was composed of densely packed red cells and had a fibrin pattern dominated by longitudinal striae which curved around the apex (fig 7). Some leucocytes were present. Platelets were not visualized either as circumscribed units or as free collections. However, star-shaped fibrin structures were present (vide infra). Wholly red structures in valve pockets were also found by Paterson (1969) who thought they were of postmortem origin allied to blood clots. However, such structures can be regarded as large red areas, without as yet secondary deposition of propagated material containing platelet-fibrin units.

CHANGES IN PLATELET-FIBRIN UNITS The outcome of the platelet component in venous (or other) thrombi is obscure and phagocytosis by invading mononuclear cells is rarely more than a minor feature. Examination of the platelet-fibrin units in different locations suggests that many undergo non-cellular retrogressive changes.

In actively growing parts, the individual platelets 




Fig 6a

Contains a number of tiny platelet-fibrin units which extend almost to the apex tip (below). PM $\times 120$.

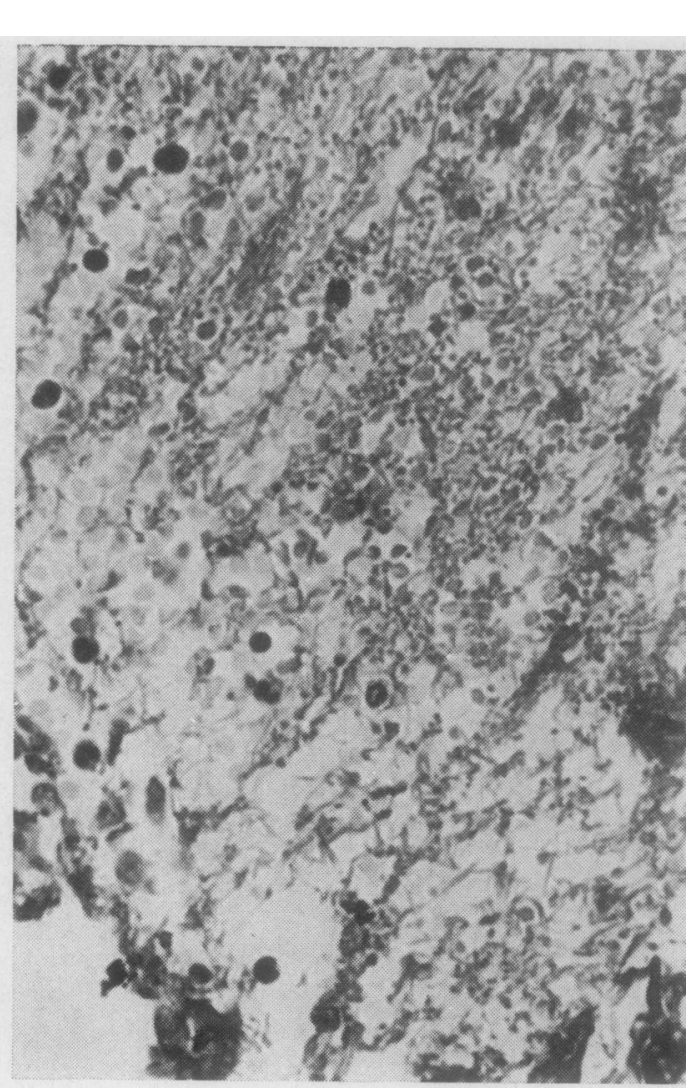

Fig $6 \mathrm{~b}$

Midline of apex of thrombus containing many diffusely arranged platelets. $P M \times 480$.

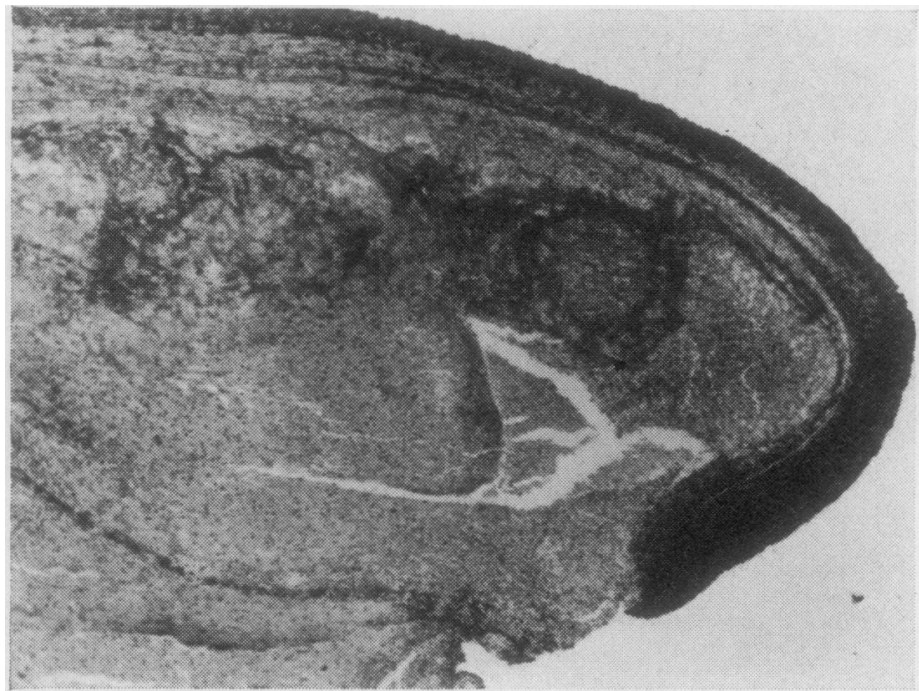

Fig 6 Distal end of valve-pocket thrombus which had become dislodged.

Distal part of the wholly red thrombus with peripheral laminated fibrin curving round the apex (right). $P M \times 30$

Fig 7 

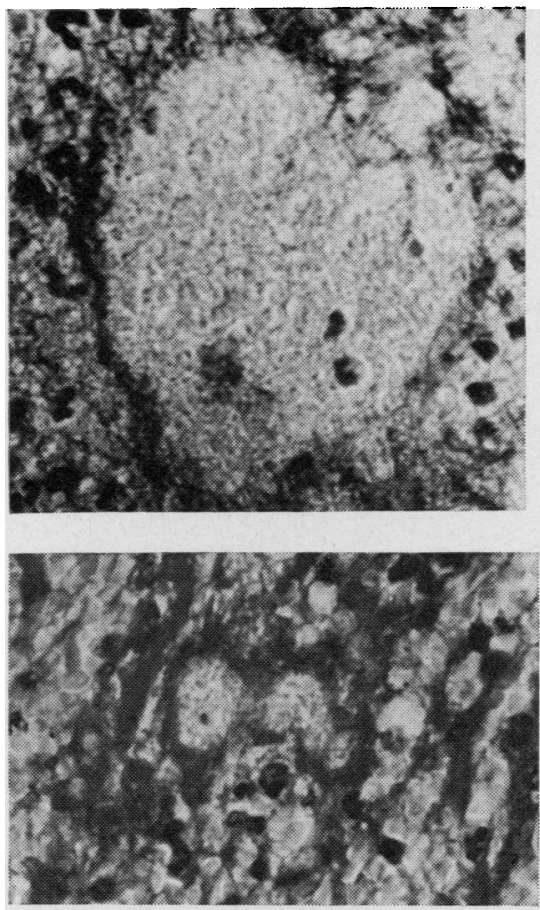

Fig $8 b$

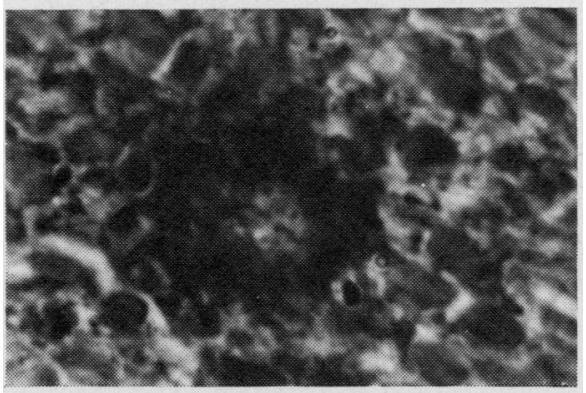

Fig $8 \mathrm{c}$

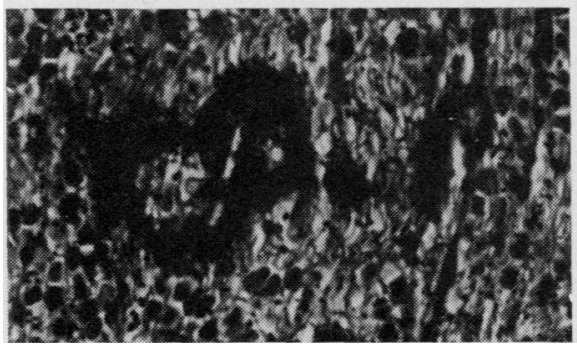

Fig 8d

Fig 8 A Large platelet-fibrin unit with defined platelet outlines. $P M \times 480$.

$B$ Tiny platelet-fibrin units with defined platelet outlines. $P M \times 480$.

C Tiny platelet-fibrin unit, plat elets recognizable but ill defined. $P M \times 1200$ (oil immersion).

$D$ Tiny fibrin rings and solid fibrin foci. No platelets visible. $P M \times 480$. within the units generally have well defined outlines when appropriately stained (fig 8a). These were probably recently formed from the flowing blood, though electron microscopy is needed to decide whether or not platelet degranulation had occurred.

Platelet-fibrin units sited distally tend to be smaller (fig 8 b) than those located proximally and are probably less recent. Platelets are unequivocally recognizable, though in some units the outlines are ill defined (fig 8c). Postmortem changes are not responsible since units with well and ill defined platelet outlines are found in the same thrombus. Further changes were observed. In some, the platelets had become transformed into a pale blue smudgy area in picromallory preparations, whilst the fibrin rim was as wide as the central zone or even wider. Sometimes irregular spaces separated groups of platelets.

Other structures, best seen in the middle and distal parts of the thrombi, are consistent with disappearance of the platelets. Some presented as small rings of fibrin (fibrin rings) surrounding debris or fibrin threads or containing a few red cells, one or two polymorphs or monocytes (fig 8d). Tiny solid foci of fibrin were also present, some starshaped from peripheral tags (fibrin stars). No platelets were recognizable and consequently the relationship to platelet-fibrin units is equivocal. Notwithstanding, the transitional appearances point to a process culminating in the disintegration and disappearance of the platelets and their replacement by foci of fibrin. This view is consistent with changes observed in haemostatic plugs and clotting blood.

PLATELETS IN RED AREAS

Special attention was paid to the red areas of recent thrombi because of the controversy concerning the nature of thrombus nidi in veins and the role or otherwise of platelets in their genesis. Serial sections failed to reveal platelet collections in the red areas of four thrombi and in the wholly red thrombus. However all contained fibrin rings, stars, and allied structures (fig 8d) which might represent the products of former platelet-fibrin units. Five other red areas did contain tiny platelet-fibrin units (figures 6a and $8 \mathrm{~b}$ ), though these were located centrally, often along fibrin seams extending to platelet-rich propagated regions. One also possessed diffuse collections of platelets extending towards the apex ' (fig 6b). In 'another red area, the platelets had been phagocytosed by infiltrating mononuclear cells.

\section{Vein Wall and Valve Cusps over Recent Thrombi}

With one exception, there was no evidence of intimal 
damage or other changes suggesting a predisposition to thrombosis in the valve pockets containing recent thrombi. In one pocket, the endothelium proximal to the adhering zone was focally elevated with a few polymorphs beneath it. In the adherent zones five thrombi showed small subintimal foci of polymorphs or lymphocytic cells, some associated with focal oedema but these were consistent with effects secondary to adhesion. Part of the endothelium distal to one thrombus had pyknotic nuclei and some swollen cells, also consistent with secondary events. Fibrous-intimal thickenings, the residue of former thrombi (Scott, 1956; Sevitt, 1973c), were observed in only two pockets, but they were small and located proximally to the zones of adherence.

No significant differences were observed between the linings of pockets with recent thrombi and those empty of thrombi or containing only very tiny thrombus fragments or condensed collections of cells (vide infra).

The valve cusps were free and unattached in all recent thrombi. They were normally thin and avascular and the endothelium seemed normal. Cusp attachment was restricted to five thrombi with extensive organization.

\section{Fat Globules in Valve-pocket Thrombi}

An unexpected finding was the presence of clear, circumscribed fat-like spaces within five thrombi, of the order of size of fat cells. Frozen sections were made of two thrombi and confirmed the fatty nature of the inclusions. There were relatively few in three thrombi and were restricted to the apical zones (fig 9). Large numbers of fat globules had been incorporated in the other two thrombi, one of which was a recent non-adherent structure (fig 10). The other was an organizing thrombus in which foamy lipophages closely surrounded many of the globules which were prominent near the adhering vein wall.

Fat emboli derived from fractures is the likely source. Four subjects had fractures restricted to the same lower limb as the fat-containing thrombi (three right, one left limb; fractured femur three cases, tibia one case). This suggests that fat globules en route from the fracture to the lung had been trapped in the valve pocket and incorporated into the forming or growing thrombus. These subjects died between three and 16 days after injury. Frozen sections prepared for fat emboli were available in three of them, and revealed moderate (two subjects) or minor lung embolism. In the fifth patient, a direct passage of globules from the fracture did not seem possible and onward passage into the femoral vein of systemically distributed fat emboli may have been responsible. That patient died nine days after

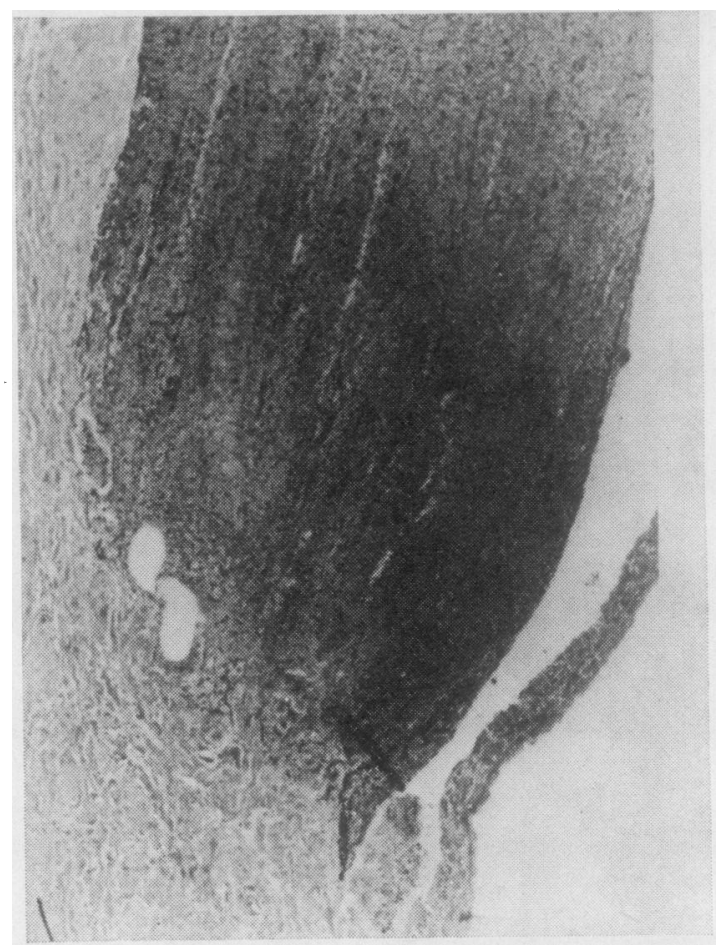

Fig 9 Two fat-like spaces towards the apex of a valvepocket thrombus. $P M \times 48$.

a fractured sternum and soft tissue injury (no limb fracture). Fat emboli were present in the lung and systemic organs.

\section{Contents of Apparently Empty Valve Pockets}

In an attempt to investigate the nature of the nidi from which thrombi form, the contents of $\mathbf{3 5}$ femoral valve pockets which seemed empty in situ, were 9 examined by serial or semi-serial histological $D$ section. They were excised from 10 injured or burned patients, mostly elderly, details of whom are N outlined in the table. Two had been given oral anticoagulant therapy. The ilio-femoral veins were $\tilde{O}$ opened by scissors and were empty of thrombi, $\underset{\omega}{\tilde{N}}$ except for a small loose thrombus in one superficial ${ }_{2}$ femoral vein, probably embolic from the calf. 0 That patient, and another, died from major pul- $\frac{\varnothing}{\Phi}$ monary embolism. Soleal vein thrombi were found $\stackrel{\odot}{\rightarrow}$ in two others.

Appropriate parts of a common or superficial femoral vein or both were excised, pinned on to corkboard, and floated on formol-saline, taking $\stackrel{\mathbb{Q}}{\varrho}$ care to disturb them as little as possible. After $\bar{\sigma}$ fixation, the specimen was trimmed into one or two 




Fig 10 Multiple fat spaces within the proximal part of a recent valve-pocket thrombus. $P M \times 30$.

valve-cusp regions. Each was divided along the midline of the cusp, thereby obtaining two longitudinally split hemi-pockets. One hemi-pocket was processed to paraffin wax and the block was cut into sections 5 microns thick in a serial or semi-serial fashion. One valve pocket was found to contain the wholly red thrombus already described. The sections from nine blocks were technically unsatisfactory.

\section{Results}

Attention was focused on circumscribed cellular collections or other structures likely to have arisen before death. They were found in 13 of the 26 hemipockets (nine subjects) considered technically satisfactory. The findings can be divided broadly into four groups viz:

1 Four pockets (three subjects) contained one, two, or more tiny fragments of condensed fibrin (fig 11). Most were closely surrounded by flat endothelial cells and a few were adherent to the intimal endothelium. They lay either on the vein
Figs 11-14 Contents of apparently empty valve pockets.

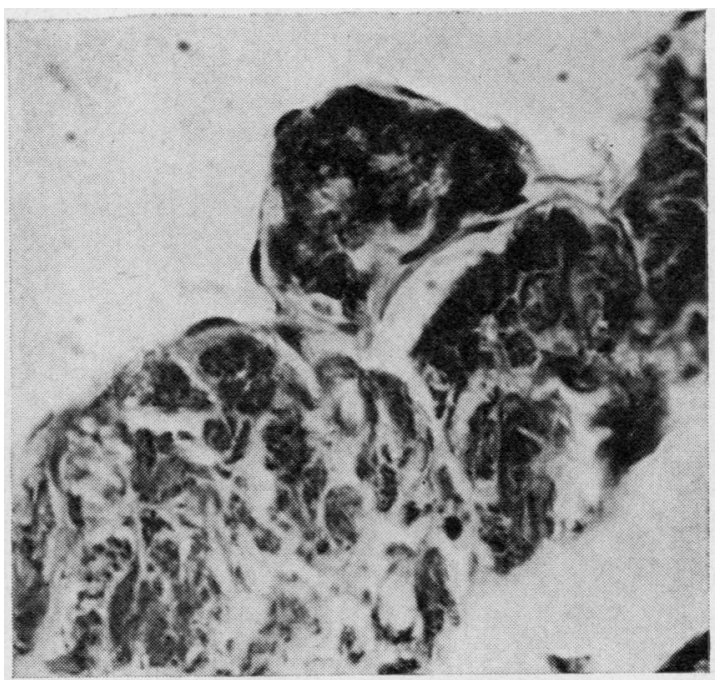

Fig 11 Fragment of fibrin surfaced by endothelial cells and slightly attached to the valve cusp (below and right). $P M \times 480$.

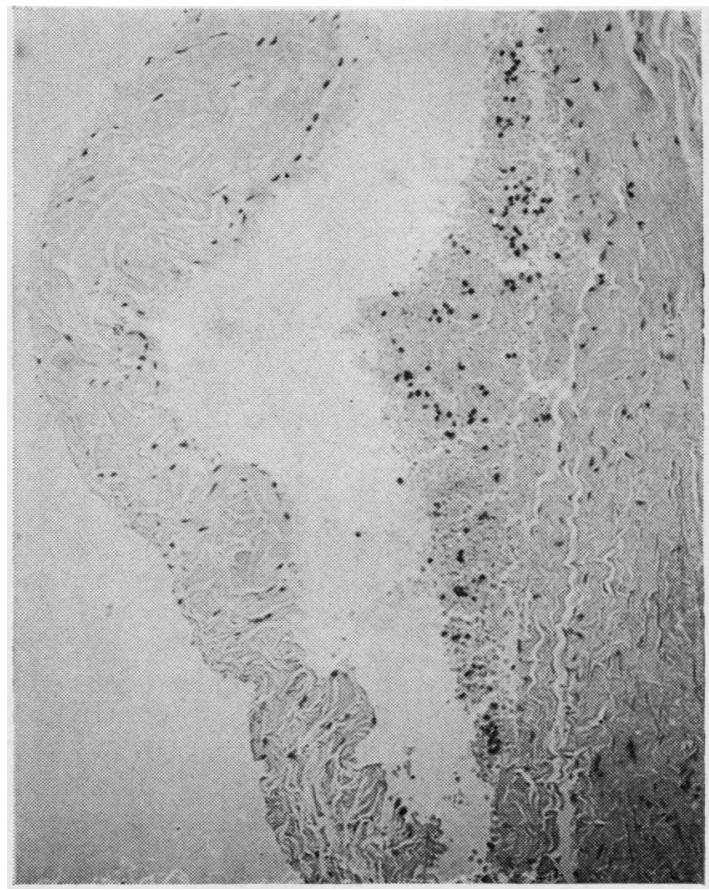

Fig 12 Valve pocket containing a fusiform mass of closely packed red cells with some leucocytes lying against the vein wall (right). Haematoxylin and eosin $(H \& E) \times 120$. 


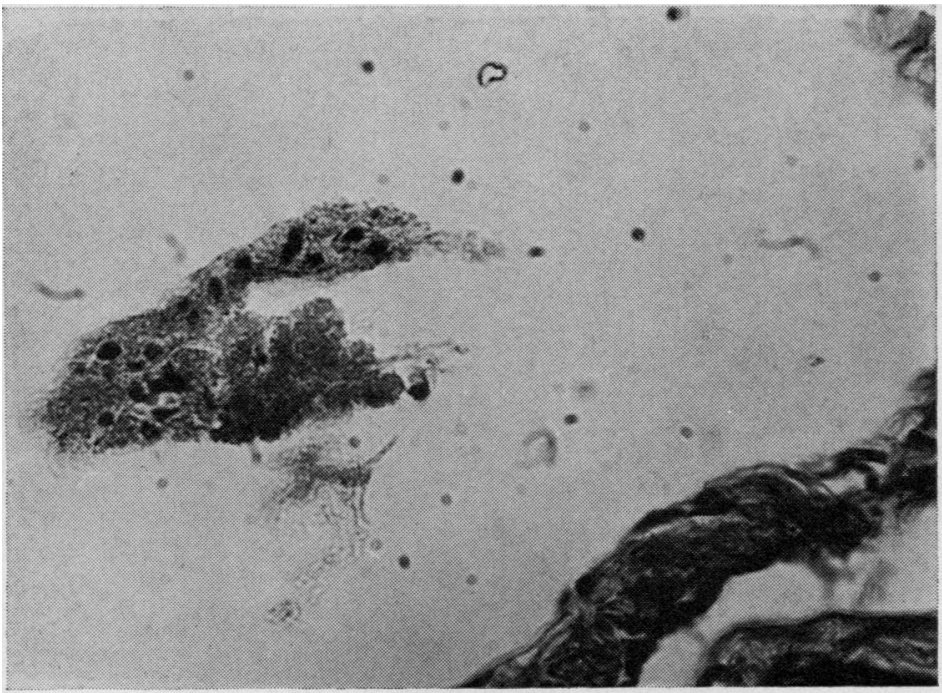

Fig 13 Clump of aggregated platelets with a few leucocytes near the valve cusp (below and right). $P M \times 480$.

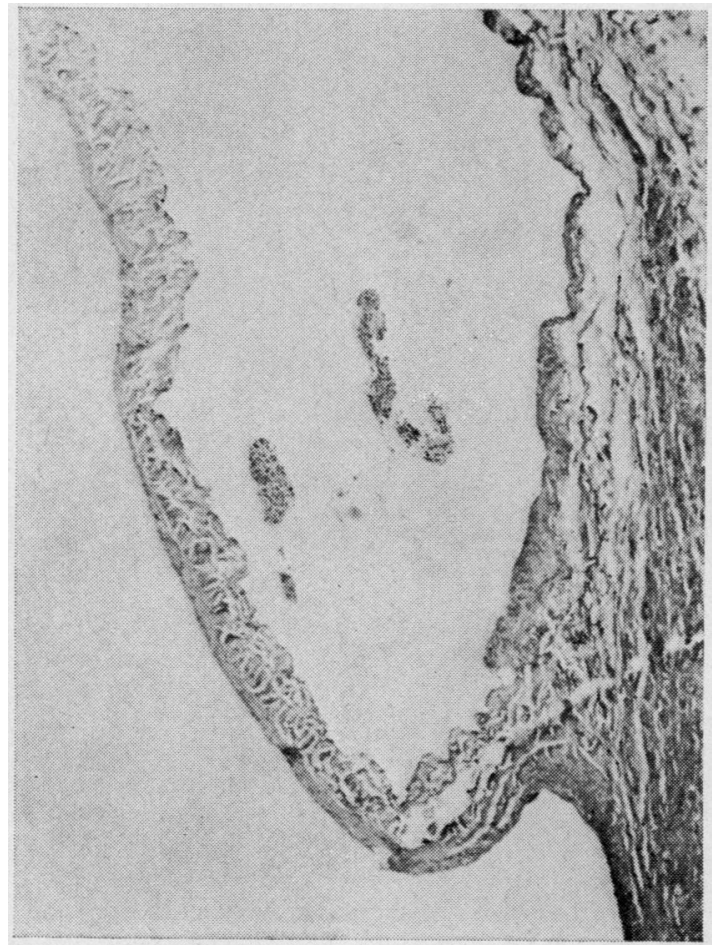

Fig 14 Valve pocket containing small masses of polymorphs. $P M \times 48$. wall or the valve leaf. They are considered to be remnants of previous small thrombi, broken up or aborted by the organic fragmentation process (Sevitt, 1973a).

2 Seven pockets contained condensed foci of red cells often with some leucocytes, protein coagulum, and a few fibrin strands. Three also contained endothelialized fibrin remnants. Three red cell collections presented as elongated strips of cells, one as a large fusiform collection (fig 12), and others as predominantly apical clumps. All were located distally in the pocket closely apposed to the intima of the vein wall or apex or both regions.

3 One pocket contained isolated clumps of aggregated platelets mixed with a few leucocytes $\frac{I}{O}$ (fig 13) or fibrin. Another contained I granular platelet collections associated with a red cell mass. N

4 One pocket contained small discrete masses of $\mathrm{N}$ polymorphs (fig 14) tangled in fibrin and with a few red cells.

\section{Discussion}

There is little doubt that valve pockets are most important primary sites of deep vein thrombogenesis (McLachlin and Paterson, 1951; Gibbs, 1957; Sevitt and Gallagher, 1959, 1961) and that venous stasis is the most important predisposing condition. However concepts of origin have been bedevilled by 
the belief that every thrombus begins as a focus of clumped platelets at a site of endothelial injury, a concept relevant to arterial thrombosis. The idea, which dates back to experimental observations made in the 19th century on the clumping of platelets at foci of vascular damage (Jones, 1850; Zahn, 1874; Bizzozero, 1882; Eberth and Schimmelbusch, 1886), was strengthened by electron microscopic studies on the key role of platelets in haemostatic plugs and at other sites of endothelial injury (Poole, 1964; French, 1965; Ashford and Freiman, 1967) and is supported by the discovery of the platelet-aggregating powers of collagen (Zucker and Borelli, 1962) probably shared with other subintimal tissues. However, its universal application was first challenged by the experimental production of platelet-poor coagulation thrombi in normal vessels under conditions of stasis after the injection of serum into another vein (Wessler, 1955).

The distal red areas in valve-pocket thrombi with their dominant red cell-fibrin structure are relevant to the issue. They are the original or oldest parts of the thrombi because early adherence and cellular invasion are localized to their regions, a feature also found by Paterson and McLachlin (1954). The laminated thrombus material containing many platelet-fibrin units, which are laid down on their surfaces, are due to subsequent growth by a mechanism involving both platelets and the coagulation system. Further, no significant changes predisposing to thrombosis were observed in valve-pocket intima either in the present study or by Paterson and McLachlin, and the slight inflammatory changes found in some cases are consistent with reactive events secondary to thrombosis or adherence to the vein. The results indicate that new valve-pocket thrombi form on normal endothelium, though of course subtle changes from hypoxia or minor splits in the endothelial lining cannot be excluded.

NATURE OF THROMBUS NIDI

The red areas, which are likely to correspond to or include the original microscopic nidi, were either platelet-free or platelet-poor, and one wholly red thrombus did not contain platelets. Some possessed a few tiny platelet-fibrin units which lay along fibrin seams connecting with propagated zones suggesting a secondary formation, and none were found near the surface adjacent to the vein wall which might have been expected if they played a primary thrombogenetic role. These findings do not suggest an important role of platelets in nidus formation, though the limitations of light microscopy and the dynamic changing structure of thrombi counsels caution. Thus, platelet masses predominate in fresh haemostatic plugs and experimental thrombi on damaged endothelium, but within a few hours they are replaced by a predominantly fibrin-red cell structure (for references, see Hume, Sevitt, and Thomas, 1970). Similar evolutionary changes might explain the absence of platelet collections in red areas, and it is conceivable that the fibrin rings and allied structures found represent the locations of previous clumps of platelets.

Endothelialized fibrin fragments, considered to be the remnants of aborted thrombi, were often found in apparently empty valve pockets. The possibility that they act as nidi for new thrombi cannot be set aside. They were not observed within recent thrombi though they could be easily overlooked.

Red cell collections, some with leucocytes, were also frequent in these pockets; an occasional pocket contained clumps of platelets and one contained small masses of polymorphonuclear leucocytes. These structures are probably silted into the pockets from the blood during venous stasis through the eddying of blood flow at the mouths of valves. They may represent the nidi from which red areas grow, though they are unstable before fibrin forms and could return to the blood stream with increase of flow. Stability would be achieved by formation of fibrin, and growth through interaction with the clumping of platelets. Local release of thrombin is likely to play a key role in these changes.

The incorporation of fat globules in some valvepocket thrombi is a new finding, and the connexion which it raises between deep vein thrombi and fat embolism from fractures is of interest. Eddy currents in valve pockets probably underlie their incorporation into forming or growing thrombi. However a thrombogenetic role is some thrombi cannot be excluded, since marrow fat is thromboplastic and fat globules were localized to the apical region in several thrombi.

\section{References}

Ashford, T. P., and Freiman, D. G. (1967). The role of the endothelium in the initial phases of thrombosis. Amer. J. Path., 50, 257-273. Bizzozero, J. (1882). Ueber einen neuen Formbestandtheil des Blutes und dessen Rolle bei der Thrombose und der Blutgerinnung. Virchows Arch. path. Anat., 90, 261-332.

Cotton, L. T., and Clark, C. (1965). Anatomical localization of venous thrombosis. Ann. roy. Coll. Surg. Engl., 36, 214-224.

Diener, L. (1971). Intraosseous phlebography of the lower limb. Postmortem investigation of thrombotic venous disease. Acta Radiologica, suppl. 304.

Eberth, J. C., and Schimmelbusch, C. (1886). Experimentelle Untersuchungen über Thrombose. Virchows Arch. path. Anat., 103, 39-87 and 105, 331-350.

French, J. E. (1965). The structure of natural and experimental thrombi. Ann. roy. Coll. Surg. Engl., 36, 191-200.

Gibbs, N. M. (1957). Venous thrombosis of the lower limbs with special reference to bed-rest. Brit. J. Surg., 45, 209-236.

Hume, M., Sevitt, S., and Thomas, D. P. (1970). Venous Thrombosis and Pulmonary Embolism. Harvard University Press, Cambridge, Mass., and Oxford University Press, London.

Jones, T. W. (1850). On the state of the blood and the blood-vessels in inflammation ascertained by experiments, injections and 
observations by the microscope. Guy's Hosp. Rep. (second series), 7, 1-100.

McLachlin, J., and Paterson, J. C. (1951). Some basic observations on venous thrombosis and pulmonary embolism. Surg. Gynec. Obstet. 93, 1-8.

Paterson, J. C. (1969). The pathology of venous thrombi. In Thrombosis, edited by S. Sherry et al., pp. 321-344. Nat. Acad. Sci., Washington D.C.

Paterson, J. C., and McLachlin, J. (1954). Precipitating factors in venous thrombosis. Surg. Gynec. Obstet., 98, 96-102.

Poole, J. C. F. (1964). Structural aspects of thrombosis. Scient. Basis Med. Ann. Rev., 55-66.

Sandritter, W. (1962). Die pathologische Anatomie der Thrombose und Lungenembolie. Behringwerk-Mitteil., 41, 37-67.

Scott, G. B. D. (1956). Venous intimal thickenings and thrombosis J. Path. Bact., 72, 543-546.

Sevitt, S. (1973a). The mechanisms of canalization of deep vein thrombosis. J. Path., 110, 153-165.

Sevitt, S. (1973b). Pathology and pathogenesis of deep-vein thrombosis. In Recent Advances in Thrombosis, edited by L. Poller, pp. 17-38. Churchill-Livingstone, Edinburgh and London.

Sevitt, S. (1973c). The vascularization of deep-vein thrombi and their fibrous residue: a post-mortem angiographic study. J. Path. 111, 1-11.

Sevitt, S., and Gallagher, N. G. (1959). Prevention of venous thrombosis and pulmonary embolism in injured patients. Lancet, 2 , 981-989.

Sevitt, S., and Gallagher, N. G. (1961). Venous thrombosis and pulmonary embolism. A clinico-pathological study in injured and burned patients. Brit. J. Surg., 48, 475-489.

Thomas, D. P. (1972). The platelet contribution to arterial and venous thrombosis. Clin. Haemat., 1, 267-282.

Wessler, S. (1955). Studies in intravascular coagulation. III. The pathogenesis of serum-induced venous thrombosis. $J$. clin. Invest., 34, 647-651.

Zahn, F. W. (1874). Untersuchungen über Thrombose: Bildung der Thromben. Virchows Arch. path. Anat., 62, 81-124.

Zucker, M. B., and Borrelli, J. (1962). Platelet clumping produced by connective tissue suspensions and by collagen. Proc. Soc. exp. biol. Med., 109, 779-787.

\section{The June 1974 Issue}

\section{THE JUNE 1974 ISSUE CONTAINS THE FOLLOWING PAPERS}

The laboratory diagnosis of tropical diseases with special reference to Britain: A review D. S. RIDLEY

The effect of bilirubin on the assay of gentamicin S. RENSHAW AND B. CORNERE

Serum gentamicin assay: A comparison and assessment of different methods I. PHILLIPS, CHRISTINE WARREN, AND S. E. SMITH

Rapid gentamicin assay by enzymatic adenylylation ELISABETH TEN KROODEN AND J. H. DARRELL

Assay of rifampicin in serum JEAN M. DICKINSON, V. R. ABER, B. W. ALlen, G. A. Ellard, AND D. A. MITCHISON

Comparative sensitivity and resistance of some strains of Pseudomonas aeruginosa and Pseudomonas stutzeri to antibacterial agents A. D. RUSSELL AND A. P. MILLS

$\alpha_{1}$ Antitrypsin deficiency and liver disease in childhood: genetic, immunochemical, histological, and ultrastructural diagnosis A. MILFORD WARD AND J. C. E. UNDERWOOD

The antigenic determinant of fibrin(ogen) measured with agglutination inhibition immunoassays AYESHA MOLLA, MARIA BENEDETTA DONATI, AND J. VERMYLEN
Automated technique for the estimation of fetal $\vec{\varphi}$ haemoglobin $S$. R. BROOK, R. S. CRANE, R. G. HUNTSMAN, T. D. de C. MARSHALL, D. S. MCLELlAN, AND M. J. SEMPLE

Coagulation fibrinolysis in sickle-cell disease P. A. GORDON, G. R. BREEZE, J. R. MANN, AND J. STUART

A rapid, simple assay for digoxin HELENA GREENWOOD, M. HOWARD, AND J. LANDON

Immunofluorescence staining for the diagnosis of herpes encephalitis A. H. TOMLINSON, I. J. CHINN, AND F. O. MaCCALLUM

Amino acid imbalance in cystinuria A. M. ASATOOR, P. S. FREEDMAN, J. R. T. GABRIEL, M. D. MILNE, D. I. PROSSER, J. T. ROBERTS, AND C. P. WILLOUGHBY

\section{Technical method}

Experience with a three-hour electron microscopy biopsy service G. ROWDEN AND M. G. LEWIS

\section{Letters to the Editor}

\section{Book reviews}

The Association of Clinical Pathologists: 92nd general meeting

Copies are still avaiable and may be obtained from the PUBLISHING MANAGER, BRITISH MEDICAL ASSOCIATION, TAVISTOCK SQUARE, LONDON, WC1H 9JR, price $£ 1.05$. 